\title{
Treatment of Giant Intracranial Aneurysms
}

\author{
X. LV, C. JIANG, Y. LI, X. YANG, J. ZHANG, Z. WU \\ Beijing Neurosurgical institute and Beijing Tiantan Hospital, Capital Medical University, Beijing China
}

Key words: endovascular treatment, giant cerebral aneurysm

\section{Summary}

We report on report the clinical outcome obtained in treatment of giant intracranial aneurysms (GAs). Between 2005 and 2007, 51 patients with 51 GAs presented at our hospital. Twentynine were treated with primary parent vessel occlusion without distal bypass and ten underwent treatment preserving the parent artery. Twelve patients could not be treated endovascularly.

Selective embolization (including two remodeling techniques and two stent-coil embolizations) resulted in only one cure. Two patients died as a result of subarachnoid hemorrhage periprocedurely. Twenty-nine patients treated primarily with parent vessel occlusion and three patients treated with covered stent were considered cured after their treatments. Only one patient treated with parent vessel occlusion experienced ischemia during follow-up, which resulted in a mild neurological deficit. Of the twelve patients who could not be treated endovascularly, one succumbed to surgery, four died while being treated conservatively, and three were lost to follow-up.

Parent artery occlusion, covered stent and coil occlusion provide effective protection against bleeding. In treatment of paraclinoid GAs of the internal carotid artery, the use of a stent, and stent-assisted coil embolization may be a pitfall.

\section{Introduction}

Although many of the technical problems associated with smaller aneurysms have been resolved for surgical approaches and are rapidly being addressed for endovascular methods, the optimal treatment of patients with cerebral giant aneurysms (GAs) has not been determined ${ }^{1-4}$. This article focuses on the endovascular techniques used to treat giant aneurysms. Giant intracranial aneurysms, defined as greater than $25 \mathrm{~mm}$, are rare intracranial lesions. They usually manifest as a result of hemorrhage, mass effect, or thromboembolism. Because of their complexity, these aneurysms often have a poor prognosis $^{5}$. To improve the grim natural history, their treatment requires in-depth preoperative and intraoperative planning. Surgical clipping of giant aneurysms is considered a high-risk procedure because of the size of the aneurysm and its neck, which is usually wide, leading to anticipated surgical difficulties ${ }^{6}$.

When a giant aneurysm cannot be clipped directly, alternative endovascular techniques such as parent artery occlusion, coil embolization, stent-coil embolization, remodeling technique or covered stent can be considered ${ }^{3,7-12}$. Classical endovascular treatment has been based on carotid occlusion by means of detachable balloons or coils ${ }^{3,13}$. The use of covered stents for intracranial vascular structures may be effective in selected cases ${ }^{4}$. We present here our recent single-center experience with the endovascular treatment of patients with very large aneurysms or GAs distal to the circle of Willis.

\section{Patients and Methods}

\section{Patients}

From January 2005 to January 2008, 51 patients presented at our hospital with GAs. There were 27 men and 24 women with a mean age of 
42 years (range, 5-78 yrs). Clinical findings are summarized in Tables 1 to 3 . Thirty patients had symptoms of mass effect including headaches, neurological deficits. Eleven patients were admitted in the delayed stage of SAH, because the patients had been transferred to our hospital for further treatment from a local hospital and were classified according to the Hunt and Hess scale: nine patients were Grade I, one was Grade II and one was Grade III.

\section{Diagnosis and locations of the GAs}

All patients underwent six-vessel digital subtraction angiography on a high resolution (1024/1024 matrix) biplane angiographic device (GE Medical Systems, Milwaukee, WI, USA). Three-dimensional angiography was available for all cases. Fifty-one intracranial GAs were discovered.

The lesions were divided into the following three groups according to angiographic features: saccular $(n=27)$, fusiform $(n=10)$, serpentine (thrombosed aneurysm with a tortuous and irregular vascular channel inside; $n=13$ ). The GAs involved the vertebral artery and basilar artery in 11 cases: proximal to the origin of the posteroinferior cerebellar artery (PICA) in two, and at the vertebrobasilar junction (VBJ) or basilar artery in nine. Two patients had GAs in the unilateral vertebral artery, one on the right side and one on the left. Twentysix patients had GAs involving the internal carotid artery (petrosal segment in one, cavernous segment in 16, and paraclinoidal segment in nine), the middle cerebral artery in six patients (M2 in three, M3 in three), and the posterior cerebral artery in eight patients (all at P2 sgment).

\section{Preprocedure evaluation}

Diagnostic cerebral angiography is crucial before final decisions on treatment options are made. Cross-compression views can aid in determining the patency of the posterior communicating and anterior communicating arteries as appropriate. Three-dimensional angiography can be extremely useful at delineating the relevent pathological anatomy. A six-vessel study is performed to define any additional aneurysms or potential anastomosis vessels. Magnetic resonance imaging can be useful to disclose intra-aneurysmal thrombus, mass effect, edema, and any potential associated ischemic lesions.

\section{Treatment options}

1. Parent vessel occlusion, when tolerated, is the endovascular therapy of choice for all large and giant aneurysms. Tolerance of carotid artery occlusion can be reliably evaluated with angiographic testing, even in patients under general anesthesia.

2 . When parent vessel occlusion is not tolerated, selective coiling is a low-risk alternative. Wide-necked aneurysms can be coiled with the assistance of a balloon or stent. Additional coiling has a low complication rate and should be performed when necessary. Late aneurysm regrowth and reopening may occur, even after stable occlusion during some years, particularly in large basilar tip aneurysms.

Patients were treated under general anesthesia. Anticoagulation was used in patients treated with endovascular techniques. In these cases, 5000U of heparin were administered at the start of the procedure, followed by $1000 \mathrm{U}$ every hour until completion. Patients treated with stent placement were premedicated with clopidogrel, $75 \mathrm{mg} /$ day, and aspirin, 300mg/day, starting three to five days before the treatment. After the procedure, heparinization was continued for 24 hours to maintain partial thromboplastin time in the range of 60-70 seconds. After systemic heparinization was discontinued, subcutaneous injection of low molecular weight heparin was given for two days. Antiplatelet agents (clopidogrel $75 \mathrm{mg}$ and aspirin $300 \mathrm{mg}$ daily) were administered transorally for six weeks. At six weeks, clopidogrel was discontinued, and aspirin was maintained indefinitely.

\section{Results}

\section{Clinical outcome of endovascular treatment}

Tables 1 to 2 list the clinical courses of 39 patients treated endovascularly. In 29 patients treated by parent artery occlusion, the immediate clinical outcomes were as follows: 26 improvements, two worsening of symptoms, and one death. Four patients, who underwent coil embolization (including two remodeling techniques) showed improvements. Three patients, who underwent stent deployment, showed a clinical improvement and two deaths. Of the six patients with GAs of the ICA treated with covered stent initially, three failed due to tortuous parent artery and were treated with coil embolization or stenting, the other three 


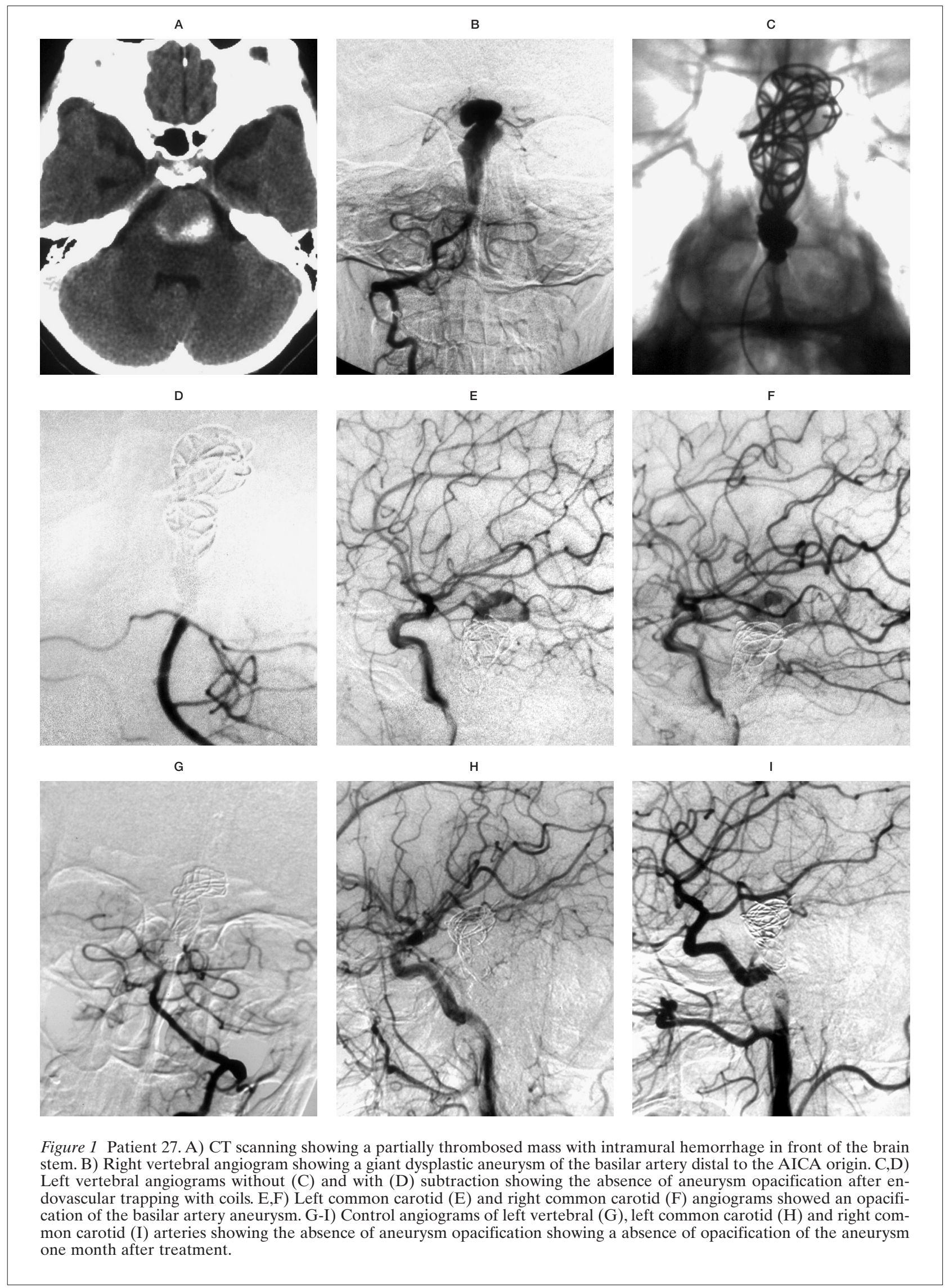


Table1 Giant intracranial aneurysms treated with parent artery occlusion.

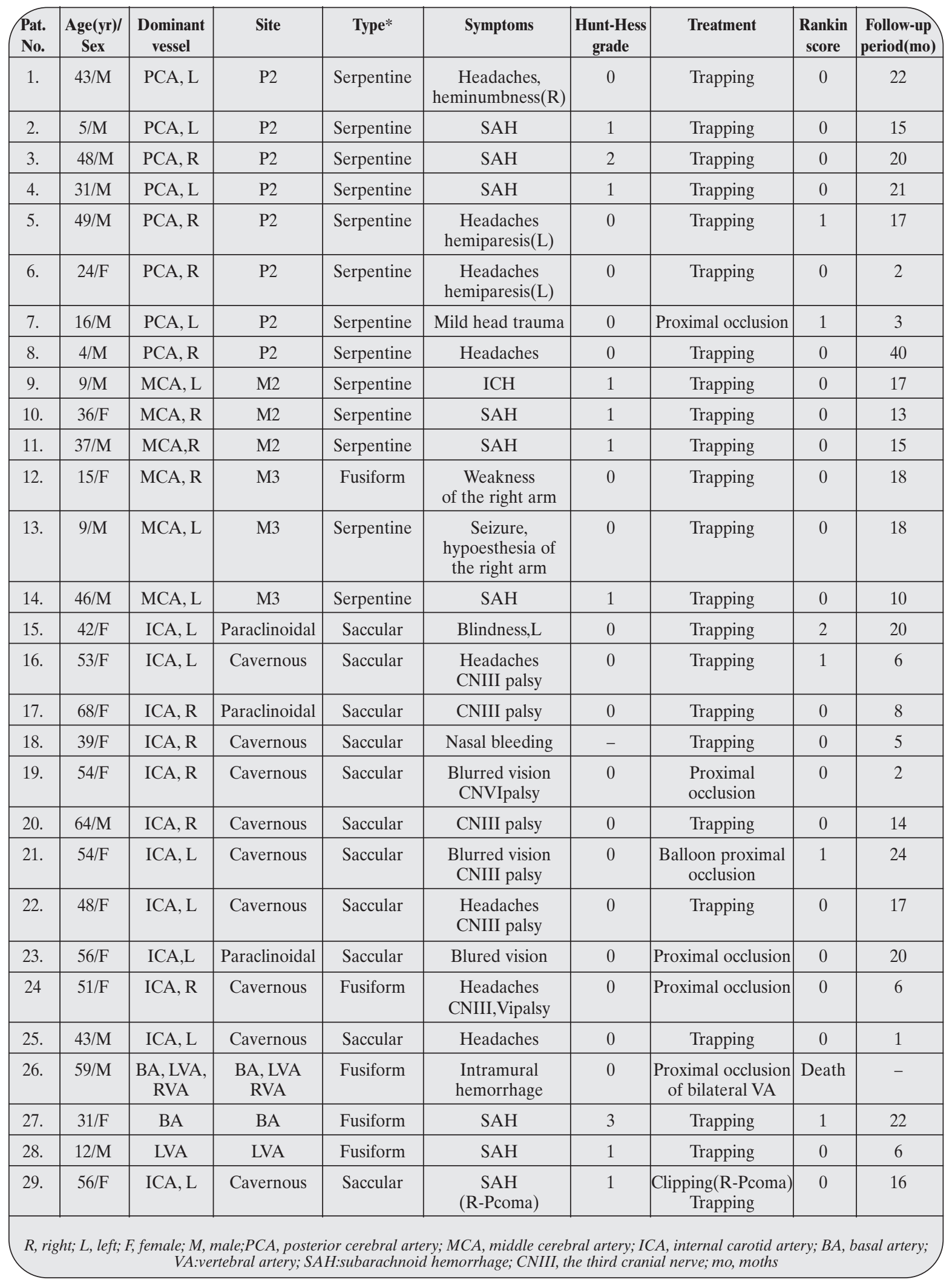


Table2 Giant intracranial aneurysms treated with coiling, stent-coiling and covered stent.

\begin{tabular}{|c|c|c|c|c|c|c|c|c|c|}
\hline $\begin{array}{l}\text { Pat. } \\
\text { No. }\end{array}$ & $\begin{array}{c}\operatorname{Age}(\mathbf{y r}) / \\
\text { Sex }\end{array}$ & $\begin{array}{c}\text { Dominant } \\
\text { vessel }\end{array}$ & Site & Type* & Symptoms & \begin{tabular}{|c|} 
Hunt-Hess \\
grade
\end{tabular} & Treatment & \begin{tabular}{|c|} 
Rankin \\
score
\end{tabular} & $\begin{array}{c}\text { Follow-up } \\
\operatorname{period}(\operatorname{mo})\end{array}$ \\
\hline 30. & $45 / \mathrm{F}$ & ICA, R & Cavernous & Saccular & CNIII palsy & 0 & $\begin{array}{l}\text { Jostent }(4.5 \times 19) \\
\text { failed Coil }\end{array}$ & 1 & 18 \\
\hline 31. & $34 / \mathrm{F}$ & ICA, L & Paraclinoidal & Saccular & Hypopitarism & 0 & Stent coiling & Death & - \\
\hline 32. & $35 / \mathrm{F}$ & ICA, L & Paraclinoidal & Saccular & None & 0 & Remodeling & 0 & 10 \\
\hline 33. & $48 / \mathrm{M}$ & ICA, L & Petrosal & Saccular & Headaches & 0 & $\begin{array}{c}\text { Jostent }(5 \times 26) \\
\text { failed Remoideling }\end{array}$ & 0 & 28 \\
\hline 34. & $55 / \mathrm{F}$ & ICA, R & Cavernous & Saccular & Diplopia & 0 & Coil & 1 & 5 \\
\hline 35. & $54 / \mathrm{F}$ & ICA, R & Cavernous & Saccular & $\begin{array}{c}\text { Trigeminal } \\
\text { neuralgia Blurred } \\
\text { vision Tinnitus }\end{array}$ & 0 & \begin{tabular}{|} 
Jostent $(4 \times 19)$ failed \\
Neuroform \\
$(4 \times 30,4 \times 20,4.5 \times 20)$
\end{tabular} & Death & - \\
\hline 36. & $56 / \mathrm{F}$ & ICA, R & Cavernous & Saccular & Diplopia & 0 & Stent coil & 0 & 6 \\
\hline 37. & $37 / \mathrm{M}$ & ICA, L & Paraclinoidal & Saccular & Epistaxis & 0 & Jostent (4x16) & 1 & 16 \\
\hline 38. & $62 / \mathrm{M}$ & ICA, R & Cavernous & Saccular & CNIII,VI palsy & 0 & Jostent (4x19) & 0 & 18 \\
\hline 39. & $40 / \mathrm{M}$ & ICA, R & Cavernous & Fusiform & CNIII,VI palsy & 0 & $\begin{array}{c}\text { Jostent } \\
(4.5 \times 16,4.5 \times 19)\end{array}$ & 0 & 24 \\
\hline
\end{tabular}

showed clinical improvements. A 31-year-old woman (Patient 31) who presented with a nonruptured giant carotid aneurysm was treated by Wingspan stent and detachable coils. Posttreatment conventional angiography revealed a partial aneurysm thrombosis, and the patient died on the seventh day from a bleed. A 54year-old woman (Patient 35) who presented with a nonruptured giant carotid aneurysm was treated by three Neuroform stents $(4 \times 30,4 \times 20$, $4.5 \times 20)$ after failure of a covered stent (Jostentt, 4x19). The patient died from bleeding six hours posttreatment. A 59-year-old man ( $\mathrm{Pa}-$ tient 26) who presented with a nonruptured giant basilar artery aneurysm with a three year history of coronary bridging was treated by bilateral vertebral artery occlusion. The patient died from heart arrest one month later. In two (Patients 13, and 27) patients who had clinical worsening, symptoms related to mass effect, including seizures, and dysphagia and progressive loss of consciousness, occurred a few hours after the procedure. The latter patient was kept intubated and on a ventilator, and intravenous corticosteroid therapy was administered for four to six days with a progressive improvement of symptoms. No technical adverse events, including vessel perforation, vessel dissection or thromboembolism, occurred.

\section{Angiographic outcome}

of endovascular treatment

Immediately after treatment, patients were evaluated by angiography to document aneurysm exclusion and patency of the parent vessel. Aneurysms $(n=29)$ treated with parent artery occlusion were totally closed in 29 patients. In one patient with a GA of cavernous carotid, the aneurysm was opacified via the ipsilateral posterior communicating artery (Pcoma) after occlusion of the ICA, and a second procedure was performed via the Pcoma to obliterated the aneurysm. Four covered stents were successfully deployed in three patients leading to total obliteration of the aneurysms with patent parent arteries. There were three technical failures secondary to proximal tortuosity, two with cavernous carotid aneurysms and one with petrosal carotid aneurysm, they were treated with stent-coil technique and coil embolization. One GA was stented only and six GAs were occluded partially.

\section{Clinical and angiographic follow-up}

All 32 patients who underwent parent vessel occlusion and covered stent deployment were considered anatomically cured, as assessed by follow-up angiography. In seven patients treated with selective embolization (including two 
remodeling techniques and two stent-coil embolizations), only one was cured with six partially embolized. These angiograms were obtained between one and ten months after treatment (mean, $6.4 \mathrm{mo}$ ). All but one parent vessel occlusions were performed with coils, which were often also placed in the aneurysm. One patient underwent parent vessel occlusion with detachable balloons. Only one patient developed ischemia three months after ICA occlusion, and exhibited persistent mild uncoordination in one hand (modified Rankin Scale scores of 1). Mean duration of clinical follow-up was 14.5 months (range, 1-40 mo). Clinical outcome was graded according to the Rankin score, modified as follows: 0 (neurologically intact, $\mathrm{n}=28$ ); 1 (mild hemiparesis, cranial nerve palsy, or other deficit that does not interfere with daily functioning or work, $n=9$ ).

\section{Untreated patients}

This group included three patients who experienced subsequent brain infarction and died (Table 3). Three aneurysms (two GAs of PCA and one GA of RVA) developed spontaneous thrombosis before endovascular treatment. The average interval between presentation and death was 13.5 months (range, 5-34 mo). Four patients (three with ICA GAs and one with BA GA) remained stable at follow-up. The other two patients were lost to follow-up.

\section{Illustrative Cases}

\section{Case 27}

A 31-year-old woman (Patient 27) who complained of acute loss of consciousness, dysphagia and gait disturbance. CT scanning revealed a partially thrombosed mass with intramural hemorrahage in front of the brainstem (Figure 1A). Conventional angiography (Figure 1B) showed a giant fusiform aneurysm of the basilar artery and the bilateral posterior communicating artery was patent.

The aneurysm was trapped with four detachable coils $(20 \times 30,14 \times 30,7 \times 20$, Microvention; $2 \times 6$, fiber coil, ev3), and angiographic control images (Figure 1C,D), obtained at the end of the procedure, revealed an opacification of the aneurysm via bilateral posterior communicating artery (Figure 1E,F). A few hours after treatment, the patient developed dysphagia and progressive loss of consciousness. He was kept intubated and on a ventilator, and intravenous cor- ticosteroid therapy was administered for four days. The clinical status of the patient improved, but the mild gait disturbance remained. One month later, angiographic follow-up demonstrated the absence of aneurysm opacification (Figure 1G-I).

\section{Case 39}

A 40-year-old man (Patient 39) presented with third and sixth cranial nerve palsy. Conventional angiography (Figure 2A) showed a $27 \mathrm{~mm}$ aneurysm of the left cavernous carotid artery. It was difficult to treat this aneurysm with remodeling or stent-coil technique. After three days premedication of $100 \mathrm{mg}$ aspirin and $75 \mathrm{mg}$ clopidogrel, the patient was treated by covered stent. Although the balloon was inflated twice with 12 atm, the aneurysm was still opacified after deployment of the first stent graft $(4.5 \times 16$, Jostent) and another stent graft (4.5x19, Jostent) was introduced. The aneurysm was completely occluded after deployment of the second stent graft. Control angiogram at six month follow-up showed a complete disappearance of the aneurysm and patent carotid artery and no clinical symptoms.

\section{Discussion}

This study shows that endovascular treatment seems safe and effective for the treatment of GAs. Worsening of symptoms, related to mass effect on the brainstem, may be observed after embolization. However, most patients showed good or excellent outcome and a decrease in size of the aneurysm in the long term. Giant aneurysms are rare, complex lesions that require meticulous planning to exclude them from the circulation ${ }^{11}$.

\section{Anatomic pecularities and hemodynamic pecularities}

Giant aneurysms are defined as aneurysms greater than $25 \mathrm{~mm}$ in diameter ${ }^{14}$ and represent $5 \%$ of all intracranial aneurysms. GAs are more frequent in male patients ${ }^{15}$, whereas internal carotid circulation giant aneurysms (mostly intracavernous) carry a female dominance. This was confirmed in the present series that included seven men and 18 women. These aneurysms may be saccular, fusiform or serpentine.

The more common saccular aneurysms have a neck that separates the aneurysm from the 


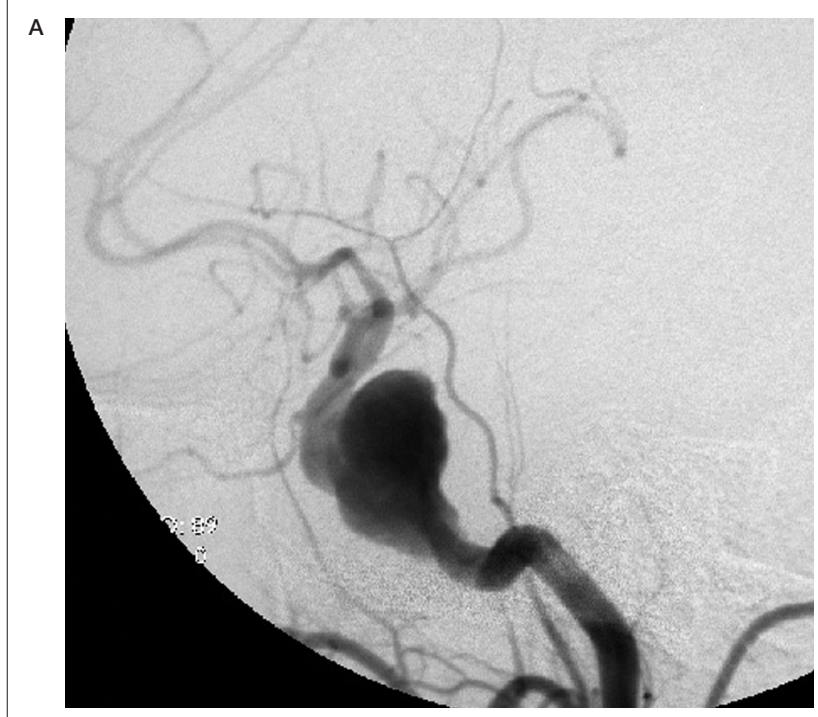

C

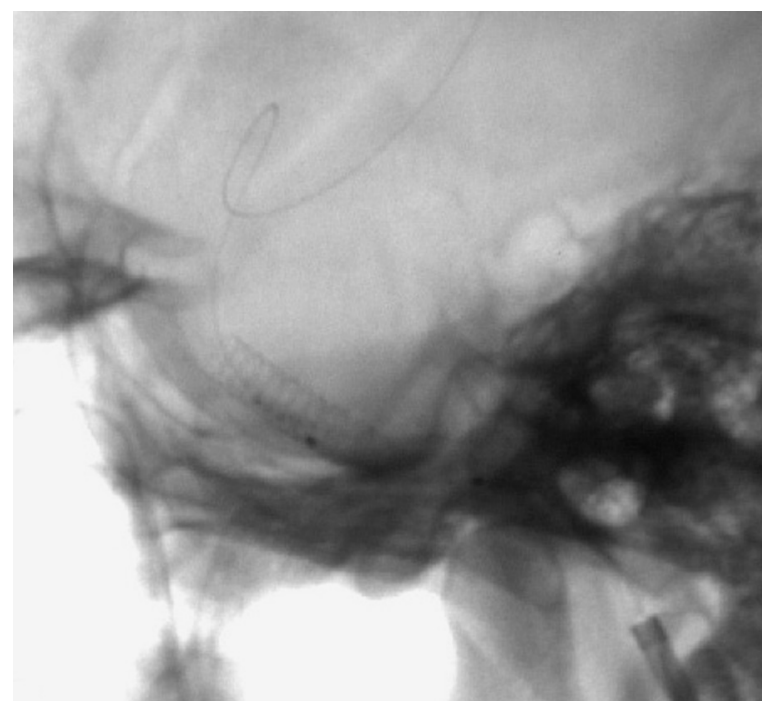

Figure 2 Patient 39. A) Left common carotid angiogram showed a giant fusiform aneurysm in the cavernous carotid artery. Although the balloon was inflated twice, the aneurysm was still opacified after deployment of the first stent graft $(4.5 \times 16)$. B,C) Left internal carotid angiograms with (B) and without (C) subtraction showing the aneurysm opacification after deployment of the first Jostent and another Jostent $(4.5 \times 19)$ was introduced. D) The aneurysm was obliterated after the second stent graft was overlapped proximal to the first. E,F) Control angiogram of left common carotid artery (frontal view) at six months after treatment showing a complete disappearance of the aneurysm and a retrograde filling of the basilar artery from the anterior circulation.

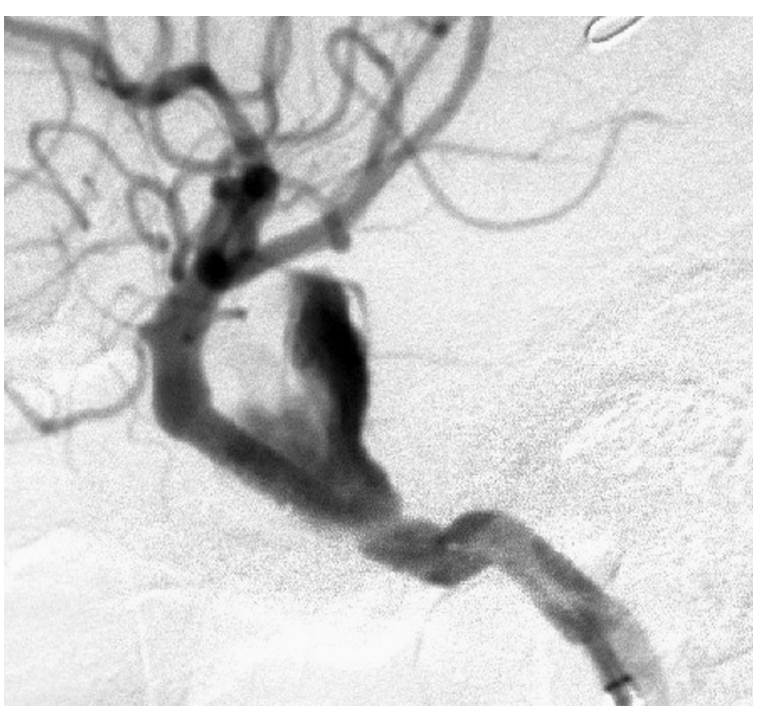

B
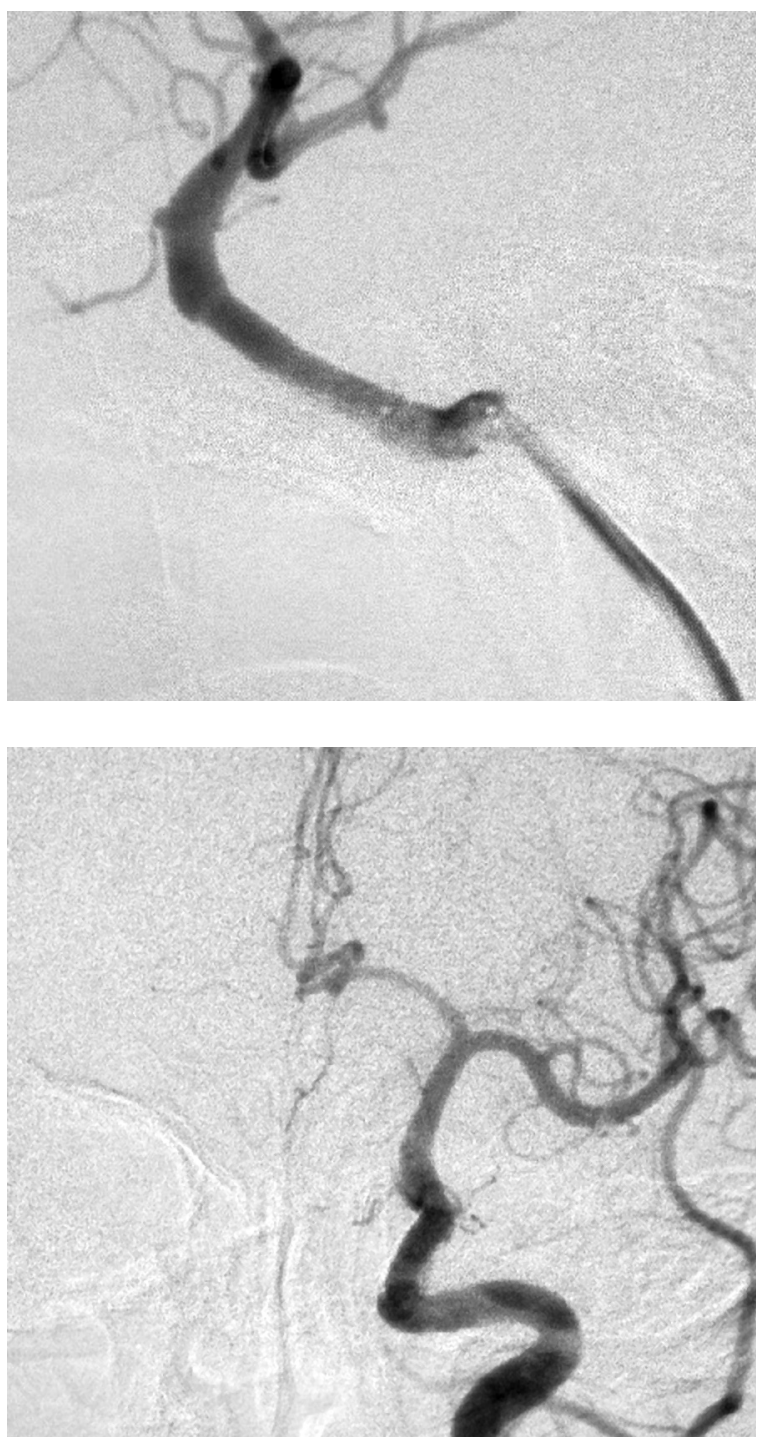
parent artery, whereas fusiform aneurysms have circumferential arterial dilation without any ostium or neck.

The serpentine aneurysm is a mostly thrombosed aneurysm with a tortuous and irregular vascular channel inside ${ }^{14}$. All of these aneurysms can present with mass effect $(60 \%$ of cases), ischemia or hemorrhage, but serpentine aneurysms are less likely to bleed ${ }^{14,16,17}$. GAs have a poor natural history ${ }^{6}$ if left untreated, and all pathophysiological features must be taken into account to perform the best treatment for the patient.

Treatment strategies are mostly influenced by the clinical presentation and the risk of SAH. Giant aneurysms that present with SAH are rare $(20 \%)$ and generally not thrombosed ${ }^{1}$. Aggressive therapeutic options should be proposed in this life-threatening situation, and the patient must be treated immediately to prevent a rebleed.

If parent artery occlusion (PAO) is planned, it should ideally be delayed after the vasospasm phase to avoid ischemic complications.
Currently, a partial coiling can be performed at the acute phase to reduce risks of rebleeding and then PAO can be performed several days later. However, most giant aneurysms present with mass effect or ischemia of thromboembolic origin. In these patients, the aims of the treatment are to decrease mass effect and prevent thromboembolic events. Aspirin therapy may be administered.

\section{Parent artery occlusion}

Our results confirm the efficacy of parent vessel occlusion for the exclusion of aneurysms from the cerebral circulation. We think that this is the optimal endovascular treatment for these lesions and should be considered in every case. Although we do not generally advocate parent vessel occlusion when the test occlusion is a failure, our results for Patient 2 demonstrates that certain patients may tolerate proximal occlusion of the distal circulation in this setting.

Therapeutic ICA occlusion and VA occlusion have been well established. There have

Table3 Giant intracranial aneurysms treated conservatively.

\begin{tabular}{|c|c|c|c|c|c|c|c|c|c|}
\hline $\begin{array}{l}\text { Pat. } \\
\text { No. }\end{array}$ & $\begin{array}{c}\text { Age }(\mathrm{yr}) / \\
\text { Sex }\end{array}$ & $\begin{array}{c}\text { Dominant } \\
\text { vessel }\end{array}$ & Site & Type* & Symptoms & $\begin{array}{l}\text { Hunt-Hess } \\
\text { grade }\end{array}$ & Treatment & $\begin{array}{c}\text { Rankin } \\
\text { score }\end{array}$ & $\begin{array}{c}\text { Follow-up } \\
\text { period(mo) }\end{array}$ \\
\hline 40. & 49/M & PCA, R & $\mathrm{P} 2$ & Saccular & $\begin{array}{c}\text { Headaches, } \\
\text { hemiparesis }(\mathrm{L})\end{array}$ & 0 & Thrombosed & 2 & 17 \\
\hline 41. & $37 / \mathrm{M}$ & PCA,L & $\mathrm{P} 2$ & Serpentine & SAH & 1 & Thrombosed & 0 & 34 \\
\hline 42. & $54 / \mathrm{M}$ & BA, LVA & BA, LVA & Fusiform & $\begin{array}{l}\text { Brian stem } \\
\text { Infarction }\end{array}$ & 0 & & Died & 15 \\
\hline 43. & $33 / \mathrm{F}$ & $\mathrm{BA}$ & $\mathrm{BA}$ & Saccular & Headache & 0 & Stable & 0 & 11 \\
\hline 44. & $56 / \mathrm{M}$ & $\begin{array}{c}\text { BA, LVA } \\
\text { RVA }\end{array}$ & BA, RVA & Fusiform & $\begin{array}{l}\text { Brian stem } \\
\text { infarction }\end{array}$ & 0 & Died & 17 & \\
\hline 45. & $63 / \mathrm{F}$ & $\begin{array}{c}\text { BA, LVA } \\
\text { RVA }\end{array}$ & LVA & Saccular & Headaches & 0 & Missed & - & - \\
\hline 46. & $60 / \mathrm{M}$ & BA, LVA & LVA & Fusiform & $\begin{array}{l}\text { Brain stem } \\
\text { infarction }\end{array}$ & 0 & Missed & - & - \\
\hline 47. & $17 / \mathrm{M}$ & RVA & RVA & Fusiform & Headaches & 0 & Thrombosed & 1 & 5 \\
\hline 48. & $62 / \mathrm{M}$ & $\begin{array}{c}\text { BA, LVA } \\
\text { RVA }\end{array}$ & BA, LVA & Fusiform & $\begin{array}{l}\text { Brain stem } \\
\text { infarction }\end{array}$ & 0 & Died & 5 & \\
\hline 49. & $43 / F$ & $\begin{array}{l}\text { ICA, R } \\
\text { ICA, L }\end{array}$ & $\begin{array}{l}\text { Cavernous } \\
\text { Paraclinoid }\end{array}$ & $\begin{array}{l}\text { Saccular } \\
\text { Saccular } \\
(3 \times 4 \mathrm{~mm})\end{array}$ & Blurred vision & 0 & $\begin{array}{c}\text { Stable } \\
\text { Remodeling }\end{array}$ & 1 & 17 \\
\hline 50. & $78 / \mathrm{F}$ & ICA, R & Paraclinoidal & Saccular & Blurred vision & 0 & Stable & 1 & 12 \\
\hline 51. & $24 / \mathrm{M}$ & ICA, R & Paraclinoidal & Saccular & Blindness, $\mathrm{R}$ & 0 & Stable & 1 & 2 \\
\hline
\end{tabular}


been several case reports of M2 branch occlusions with minimal or no deficits ${ }^{14,16,17}$.

In our experience, occlusion of the PCA in the P2 segment is well tolerated in cases of GAs, because of the rich supply of anastomotic vessels in the medial temporal lobe ${ }^{14,17}$. This is enhanced by the progressive hemodynamic changes that are induced by the development of the aneurysm, which plays the role of a reservoir. Indeed, we have frequently, if not always, observed slowing of flow in the distal territory of the PCA in cases of GAs. Parent vessel occlusions in this series were usually performed with coils because, if possible, we endeavored to pack the aneurysm, as well as the adjacent parent vessel, with coils to ensure early thrombosis of the aneurysm.

\section{Coil embolization}

Although aneurysm coiling has been demonstrated to provide good early protection from aneurysmal rebleeding, coil impaction remains a problem for large aneurysms and GAs, for which subsequent treatments are very often necessary ${ }^{11}$.

The rehemorrhage and death rates for coiltreated GAs have been demonstrated to be higher than those for their smaller counterparts. This is especially relevant for partially thrombosed aneurysms, because the coils invariably settle within the thrombus and cause the aneurysm to recanalize. Coiling, however, may provide a degree of protection from early rebleeding for some patients with large aneurysms and GAs that have bled, and we recently used packing in these situations to gain time, so that proximal occlusion, with or without distal bypass, can be used after vasospasm has subsided.

\section{Reconstructive options}

New devices developed in recent years have converted previously untreatable aneurysms into low-risk, treatable aneurysms. The use of more flexible intracranial stents in addition to coils has proved a good alternative to earlier techniques such as parent artery occlusion, which are not always tolerated by patients. In case of poor tolerance of test occlusion, different treatment options should be considered, including stenting and covered stent deployment.

The first stent designed for intracranial use was the Neuroform device (Boston Scientif- ic) ${ }^{18}$. The Leo stent has been designed to combine high radial force and easy delivery ${ }^{19}$. The high radial force reduces the possibility of stent displacement after deployment. The flexibility of the Leo stent greatly facilitates navigation of the tortuous cerebral vasculature to distal landing zones. In addition, even the tortuous arterial segments themselves, such as the carotid siphon, can be stented. Thanks to its retractability, the stent could be precisely positioned in most cases. The Wingspan stent system can also be used to assist coil embolization of cerebral aneurysms.

\section{Covered stent}

No covered stent specifically designed for intracranial use is currently available, but the Jostent coronary stent-graft has proven to be effective in a limited group of patients with intracranial vascular lesions ${ }^{4,20}$. When good support is achieved, it is sufficiently flexible to reach intracranial vascular structures without significant difficulty. Concerns about primary and subacute patency rates with these devices prompted us to perform a selective left ICA injection with simultaneous external compression of the right common carotid artery. Complete filling of right hemisphere vascularization was demonstrated without any delay in the parenchymal or venous phases. On the basis of these findings, there was less cause for concern about possible occlusion or stenosis complications at the parent artery. Although their long-term patency is still unknown, these devices could be a good alternative to the more technically challenging surgical approach or the classical parent artery occlusion technique for some patients with symptomatic giant aneurysms in the cavernous siphon.

\section{Role of neurosurgery in treatment of GAs}

Direct surgical clipping remains the definitive treatment for most aneurysms, and there are several published series of GAs occluded with clips with excellent results ${ }^{21}$. However, in their experience, the majority of distal (internal carotid artery bifurcation, MCA, or ACA aneurysms) could not be directly clipped and were treated with proximal occlusion, with or without distal bypass ${ }^{2,22}$. For the group of patients with more distal lesions, therefore, it is probably not unreasonable to subject patients directly to endovascular assessments and plan for endovascular procedures if possible. 


\section{Conclusions}

Despite major advances in endovascular options for managing patients with GAs, PAO remains a safe and effective treatment. This treatment can be carried out with minimal morbidity and mortality using clinical and angiographic monitoring. In treatment of paraclinoid GAs of internal carotid artery, the use of a stent, or stent-assisted coil embolization may be a pitfall. Treatment of giant symptomatic aneurysms located at the paraclinoidal carotid artery represents a complex pathologic entity in which the ideal technical approach has yet to be defined.

\section{References}

1 Gonzalez NR, Duckwiler G et Al: Challenges in the endovascular treatment of giant intracranial aneurysms. Neurosurgery 59(S3): 113-124, 2006.

2 van Doormaal T, van der Zwan A et Al: Treatment of giant and large internal carotid artery aneurysms with a high-flow replacement bypass using the excimer laser-assisted nonocclusive anastomosis technique. Neurosurgery 59(4) ONS(2): 328-335, 2006.

3 Van Rooij WJ, Sluzewski M et Al: Carotid balloon occlusion for large and giant aneurysms: Evaluation of a new test occlusion protocol. Neurosurgery 47: 116-121, 2000.

4 Yi AC, Palmer E et Al: Endovascular treatment of carotid and vertebral pseudoaneurysms with covered stents. Am J Neuroradiol 29: 983-987, 2008.

5 Hanel RA, Spetzler RF: Surgical treatment of complex intracranial aneurysms. Neurosurgery $62(6$ Sup 3): 1289-1299, 2008.

6 Spetzler RF, Riina HA, Lemole GM Jr: Giant aneurysms. Neurosurgery 49: 902-908, 2001.

7 Lylyk P, Miranda C et Al: Curative endovascular reconstruction of cerebral aneurysms with the pipeline embolization device: the Buenos Aires experience. Neurosurgery 64(4): 632-423, 2009.

8 van Rooij WJ, Sluzewski M: Endovascular treatment of large and giant aneurysms. Am J Neuroradiol 30(1): 12 8, 2009.

9 Geyik S, Yavuz K et Al: Endovascular treatment of intracranial aneurysms with bioactive Cerecyte coils: effects on treatment stability. Neuroradiology 50(9): 787 793, 2008.

10 Cekirge HS, Saatci I et Al: Intrasaccular combination of metallic coils and onyx liquid embolic agent for the endovascular treatment of cerebral aneurysms. J Neurosurg 105(5): 706-712, 2006.

11 Wehman JC, Hanel RA et Al: Giant cerebral aneurysms: endovascular challenges. Neurosurgery 59(5 Sup 3): S125-138, 2006

12 Biondi A, Jean B et $\mathrm{Al}$ : Giant and large peripheral cerebral aneurysms: etiopathologic considerations, endovascular treatment, and long-term follow-up. Am J Neuroradiol 27(8): 1685-1692, 2006.

13 Lv X, Li Y, Wu Z: Endovascular management for bilateral ophthalmic segment "kissing aneurysms" presenting with nasal bleeding: case report. Neuroradiol J 21: 266-269, 2008.
$14 \mathrm{Lv} \mathrm{X}, \mathrm{Li} \mathrm{Y}$ et Al: Endovascular treatment of intracranial giant serpentine aneurysms. Neuroradiol J 20(2): 237-241, 2007.

15 Lubicz B, Leclerc X et Al: Giant vertebrobasilar aneurysms: endovascular treatment and long-term follow-up. Neurosurgery 55(2): 316-326, 2004.

$16 \mathrm{Li} \mathrm{Y,} \mathrm{Lv} \mathrm{X} \mathrm{et} \mathrm{Al:} \mathrm{Endovascular} \mathrm{treatment} \mathrm{of} \mathrm{posterior}$ cerebral artery aneurysms. Neuroradiol J 21: 128-136, 2008.

17 Ross IB, Weill A et Al: Endovascular treatment of distally located giant aneurysms. Neurosurgery 47: 1147$1152,2000$.

18 David F, Felipe A et Al: Usefulness of the Neuroform stent for the treatment of cerebral aneurysms: results at initial(3-6-mo) follow-up. Neurosurgery 56(6): 11911202, 2005.

19 Kis B, Weber W et Al: Elective treatment of saccular and broad-necked intracranial aneurysms using a closed-cell nitinol stent (Leo). Neurosurgery 58(3): 443450, 2006.

20 Saatci HI, Cekirge MS et Al: Treatment of internal carotid artery aneurysms with a covered stent: experience in 24 patients with mid-term follow-up results. Am J Neuroradiol 25: 1742-1749, 2004.

21 Nonaka T, Haraguchi K et Al: Clinical manifestations and surgical results for paraclinoid cerebral aneurysms presenting with visual symptoms. Surg Neurol 67(6): 612-919, 2007.

22 Zhang Y. Jonathan, Barrow, Daniel L, Day, Arthur L: Extracranial-intracranial vein graft bypass for giant intracranial aneurysm surgery for pediatric patients: Two technical case reports. Neurosurgery 50(3): 663-668, 2002

Zhongxue Wu, MD

Beijing Neurosurgical institute and Beijing Tiantan Hospital

Capital Medical University, Beijing, China

6, Tiantan, Xili, 100050, Beijing, China

E-mail: ttyyzjb@sina.com. 